\title{
REVIEW
}

\section{The Role of Purported Mucoprotectants in Dealing with Irritable Bowel Syndrome, Functional Diarrhea, and Other Chronic Diarrheal Disorders in Adults}

\author{
Carmen Alonso-Cotoner (D) - Mar Abril-Gil (D) - Mercé Albert-Bayo (D) • \\ John-P. Ganda Mall (D) · Elba Expósito (D) · Ana M. González-Castro (D) • \\ Beatriz Lobo (D) · Javier Santos (D)
}

Received: January 12, 2021 / Accepted: February 16, 2021 / Published online: March 18, 2021

(C) The Author(s) 2021

\begin{abstract}
Chronic diarrhea is a frequent presenting symptom, both in primary care medicine and in specialized gastroenterology units. It is estimated that more than $5 \%$ of the global population suffers from chronic diarrhea. and that about $40 \%$ of these subjects are older than
\end{abstract}

C. Alonso-Cotoner · B. Lobo $(\bowtie) \cdot J$. Santos $(\bowtie)$ Servei de Aparell Digestiu, Vall d'Hebron Hospital Universitari, Passeig Vall d'Hebron 119-129, 08035

Barcelona, Spain

e-mail: beatriz.lobo@vhir.org

J. Santos

e-mail: javier.santos@vhir.org

C. Alonso-Cotoner · M. Abril-Gil · M. Albert-Bayo .

J.-P. G. Mall · E. Expósito · A. M. González-Castro .

B. Lobo $\cdot$ J. Santos

Grup de Neuro-Inmuno-Gastroenterología, Unitat

de Fisiología I Fisiopatología Digestiva, Vall

d'Hebron Institut de Recerca (VHIR), Barcelona, Spain

C. Alonso-Cotoner · B. Lobo · J. Santos

Universitat Autònoma de Barcelona, Facultat de

Medicina, Bellaterra, Barcelona, Spain

C. Alonso-Cotoner · J. Santos

CIBER de Enfermedades Hepaticas y Digestivas (CIBERHED), Instituto de Salud Carlos III, Madrid, Spain

J.-P. G. Mall

Department of Biomedical and Clinical Sciences,

Linköping University, Linköping, Sweden
60 years. The clinician is frequently faced with the need to decide which is the best therapeutic approach for these patients. While the origin of chronic diarrhea is diverse, impairment of intestinal barrier function, dysbiosis. and mucosal micro-inflammation are being increasingly recognized as underlying phenomena characterizing a variety of chronic diarrheal diseases. In addition to current pharmacological therapies, there is growing interest in alternative products such as mucoprotectants, which form a mucoadhesive film over the epithelium to reduce and protect against the development of altered intestinal permeability, dysbiosis, and mucosal micro-inflammation. This manuscript focuses on chronic diarrhea in adults, and we will review recent evidence on the ability of these natural compounds to improve symptoms associated with chronic diarrhea and to exert protective effects for the intestinal barrier.

Keywords: Adults; Bismuth subsalicylate; Chronic diarrhea; Gelatine tannate; Mucoprotectans; Mucus; Smectite intestinal permeability; Xyloglugan 


\section{Key Summary Points}

Chronic diarrhea is among the top five causes of disability for all ages and diseases.

Specific diets and mechanistic-targetedtherapy, not devoid of adverse effects, are only available for a subset of disorders.

If not treatable with specific therapy, chronic diarrhea often needs long-term symptomatic empiric antidiarrheal therapy with opiate antidiarrheals and bile acid sequestrants.

Impairment of the intestinal barrier with changes in epithelial permeability, mucus layer, and immune activation have been increasingly implicated in the initiation and perpetuation of a variety of diseases associated with chronic diarrhea.

In this setting, mucosal protectors emerge as a new alternative or complementary therapy for a more efficient and safe control of symptoms in disorders associated with chronic diarrhea, although additional studies are needed to confirm if they are cost-effective in the treatment of chronic diarrhea.

\section{DIGITAL FEATURES}

This article is published with digital features, including a summary slide, to facilitate understanding of the article. To view digital features for this article, go to https://doi.org/10.6084/ m9.figshare.14039030.

\section{INTRODUCTION}

In adults, chronic diarrhea is a leading cause of consultation in primary and secondary care [1], and shows a significant negative impact on health-related quality of life, high healthcare utilization, and increased economic burden, with direct and indirect costs estimated to reach USD492 and 129 million, respectively, in the United States in 1998 [2-4]. In 2019, the global burden of disease study reported diarrheal diseases, defined as three or more loose stools in a $24-\mathrm{h}$ period, as the fifth ranked, causing 3.2\% (2.6-4.0) of disability-adjusted life-years (DALYs) for all ages and diseases [5]. Moreover, in 2019, 6.58 billion [95\% uncertainty intervals (UI) 6.05-7.14] incident cases and 99.0 million (92.1-106) prevalent cases of diarrheal diseases contributed to 1.53 million (1.09-2.22) deaths and 80.9 million (65.4-103) DALYs. The most DALYs occurred in children under 5 years [ 45.5 million (35.8-58.3)]. Virtually all patients will experience diarrhea at some point in time, as indicated by prevalence rates [ci': 1312.4 per 100,000 (1218.9-1412.5); 9: 1286.7 per 100,000 (1192.4-1389.0)], and incidence rates [ci': $87,105.0$ per 100,000 (80131.1-94,668.2); 9 : $85,249.4$ per $100,000 \quad(78,405.9-92,593.8)]$. These rates were slightly higher among men compared to females, while mortality rates [ci': 20.7 per 100,000 (15.3-31.6); 9: 21.2 per $100,000 \quad(12.6-31.4)]$ were slightly higher among females compared to males [5].

Several definitions for chronic or persistent diarrhea have been proposed over the years. While patients' concept of diarrhea is mostly related to decreased stool consistency [6], doctors' concept is somewhat more pragmatic and incorporates various terms including stool frequency, consistency, volume or weight, and duration of symptoms. Stool frequency ( $>3$ bowel movements per day) is a commonly used criterion [7-9]. Consistency refers to the waterholding capacity of fecal solids, but this is difficult to quantify in clinical practice and stool is predominantly water (60-85\%), hence the Bristol stool chart (BSFS) [10] for assessing consistency is recommended [11]. In contrast, stool weight or volume ( $>200 \mathrm{~g} /$ day) are not recommended any more as a sole measure of chronic diarrhea because up to $20 \%$ of patients with watery diarrhea, who have a lower stool weight, are not included in this definition, and because stool weights vary greatly and 'normal' stool volumes can easily exceed this value [12]. Although there is no consensus on the duration 
of symptoms, most authors would accept that diarrhea persisting for longer than 4 weeks is a reasonable limit to differentiate acute from chronic diarrhea [2]. Therefore, a comprehensive and pragmatic definition of chronic diarrhea incorporates all these elements [12]: the presence of more than 3 stools per day; stool consistency between types 5 and 7 on the BSFS; and duration greater than 4 weeks.

Although difficult to estimate due to variations in definition and socio-demographic differences across populations, in two population surveys, Talley et al. reported a prevalence of 'chronic diarrhea', defined as loose, watery stools often and/or stool frequency of more than three stools per day, of between 4 and 5\% in a predominantly middle-aged white population without the presence of abdominal pain, and of between 7 and $14 \%$ in those with abdominal pain (i.e., 'functional bowel disease') [13]. Other studies have reported the combined prevalence in a general population of irritable bowel syndrome with predominant diarrhea (IBS-D) and functional diarrhea using the Rome II questionnaire with figures of $3.3 \%$ in China [14], 8.8\% in Norway [15], and $13.5 \%$ in Canada [16]. More recently, the prevalence of chronic diarrhea in adults, defined as types 6 or 7 rating on the BSFS, was $6.6 \%$ [95\% confidence interval (CI) $5.8,7.4$ ] in a nationally representative sample of US adults [17]. In this study, after a multivariable analysis, women were 1.7 times more likely to have chronic diarrhea than men $(P=0.001)$. The prevalence of chronic diarrhea also increased with increasing age $(P<0.001)$. The most recent and largest epidemiologic study performed by experts of the Rome Foundation (https://theromefoundation.org/) included 73,076 adult respondents from 33 countries in whom the diagnosis of IBS-D and functional diarrhea was raised in the internet survey $(54,127$ respondents) in $1.2 \%(1.1-1.3)$ and 4.7 (4.5-4.9), respectively [18]. In this study, prevalence rates were substantially increased for women with IBS-D and for men with functional diarrhea, and health-related quality of life was lower compared to those without these disorders.

Chronic diarrhea has a broad differential diagnosis, including both organic and functional disorders of the gut, as well as a growing list of drugs/herbal medications and systemic disorders like diabetic neuropathy or systemic sclerosis $[1,12,19,20]$. Among organic gut disorders, the main causes include infection, particularly persistent travelers' diarrhea, celiac disease, inflammatory bowel disease, microscopic colitis, bile acid-induced diarrhea, small intestinal bacterial overgrowth, carbohydrate malabsorption, exocrine pancreatic insufficiency, bowel resection, radiation enteritis, and colon cancer [21, 22]. Among functional bowel disorders, functional diarrhea and IBS-D are the leading disorders associated with chronic diarrhea.

Management of chronic diarrhea depends greatly on the identification of the causative problem and comprehension of the underlying pathophysiology, which usually relies on a work-up for chronic diarrhea including personal and family history, careful review of current medications, physical examination, laboratory, microbiological and hydrogen breath tests, and imaging and endoscopic techniques [22]. When the cause is identified, specific diet and therapy aimed at the underlying pathophysiology are initiated. If not treatable with specific therapy, chronic diarrhea often needs long-term symptomatic empiric antidiarrheal therapy, where opiate antidiarrheals and bile acid sequestrants remain as the mainstay, to mitigate symptoms in most patients. However, long-term use of these drugs may lead to misuse and abuse, which has been related to serious heart problems in the case of loperamide (https://www. fda.gov/drugs/drug-safety-and-availability/fdadrug-safety-communication-fda-warns-aboutserious-heart-problems-high-doses-antidiarrhe al), and to common side effects and interference with nutrient, vitamin, and drug absorption in the case of cholestyramine https://www.drugs. $\mathrm{com} / \mathrm{sfx} /$ cholestyramine-side-effects.html).

\section{Definition of Mucoprotectans and Rationale for Their Use in the Management of Chronic Diarrhea}

Antidiarrheal drugs can be broadly defined as agents that minimize the symptoms of diarrhea 
by improving stool consistency, reducing stool frequency, or reducing stool weight by specific or ill-defined/nonspecific mechanisms of action [23]. The category of agents used for nonspecific treatment of diarrhea includes adsorbents, minerals, stool texture modifiers, and mucoprotectants that work intraluminally to modify enteric contents.

A recent review and one meta-analysis report the clinical efficacy of gelatin tannate (GT) [24], xylogucan (XG), and other mucoprotectants [25] for acute diarrhea in children and adults. Therefore, this review focuses on chronic diarrhea in adults, and on the rationale for using mucoprotectants as an alternative or complementary therapy for dealing with chronic diarrhea and major associated symptoms.

Mucoprotectans are products that share the ability of creating a film-forming barrier over the intestinal mucosa, helping to reduce the

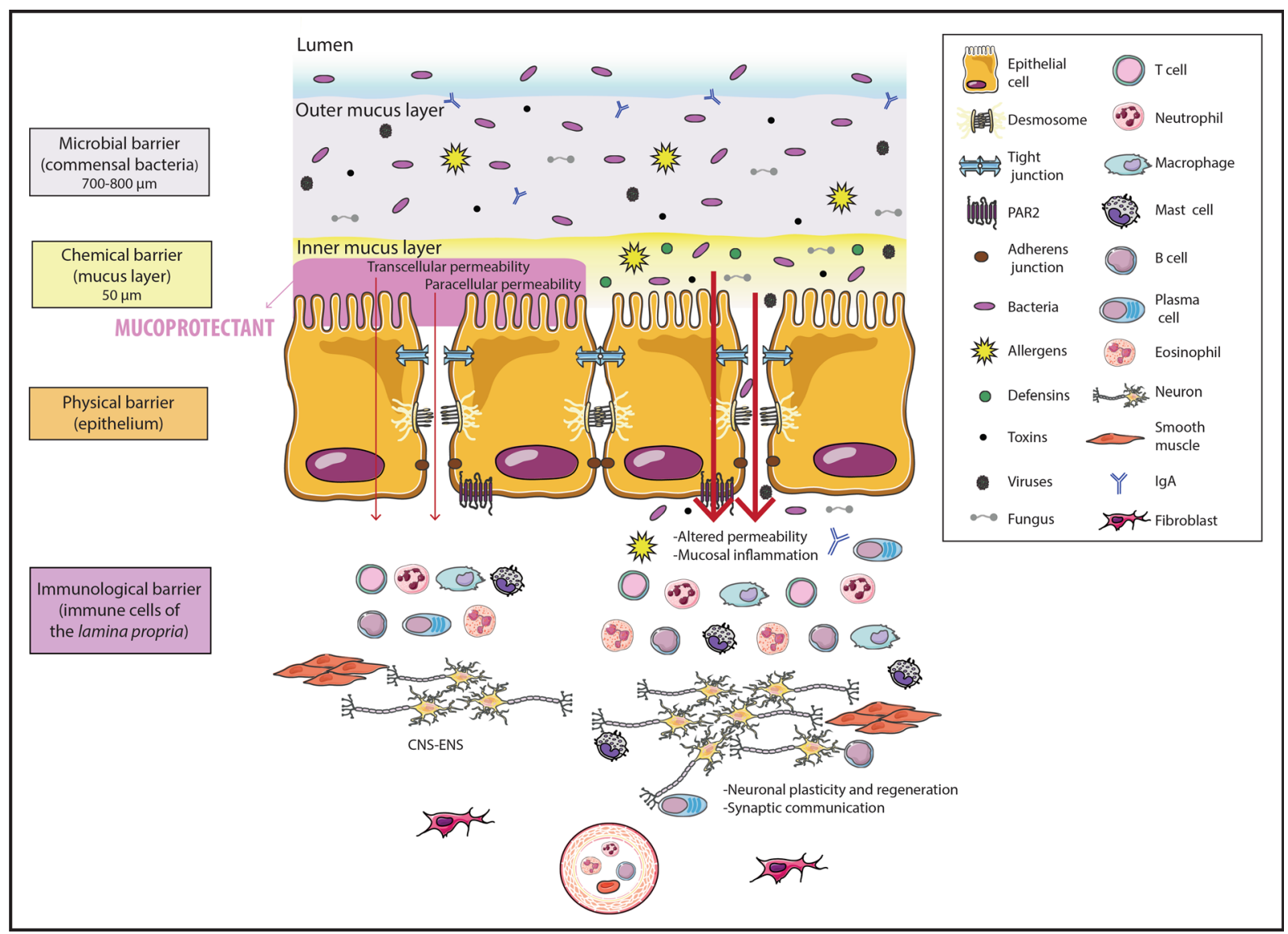

Fig. 1 Mechanism of action of mucoprotectants. When the mucus layer is damaged, access by pathogens, toxins, allergens, and irritants across the intestinal barrier is granted, which may enhance intestinal epithelial permeability and inflammatory and immune responses of resident immunocytes within the lamina propria. This response, in turn, may lead to further distortion of intestinal permeability and perpetuation of mucosal lowgrade inflammation, increasing apposition/communication between immune cells, such as mast cells and plasma cells, and nerve endings, neuronal plasticity, and regeneration affecting the enteric nervous system (ENS) and afferent routes to the central nervous system (CNS). Mucoprotectans like xyloglucan and gelatin tannate share mucoadhesive properties and the ability of creating a film-forming barrier over the intestinal mucosa or protect the mucus layer, helping to preserve intestinal permeability and avoid or decrease mucosal inflammation, reducing the effect of noxious agents on the intestinal barrier. Other molecules, such as bismuth subsalicylate or smectite, may protect the mucus layer via complex mechanisms 
effect of pathogens and to improve the function of the intestinal barrier (Fig. 1). Several mucoprotectant products, classified as medical devices classes IIa or III, have been approved in European countries, Israel, and Turkey for the restoration of the physiological functions of the intestinal wall and the treatment of diarrhea. Similarly, GT has been approved as a drug or as intermediate agent for the treatment of diarrhea in Mexico, and in some countries in Africa and south-east Asia. Other agents, such as bismuth subsalicylate (BSS) and smectite, may also show barrier-enhancing properties and, therefore, are included in this review.

The intestinal barrier consists of a series of contiguous layers, beginning on the lumenal surface with the commensal microbiota and the mucus layer, extending to the columnar epithelium and extracellular matrix which lie beneath them, and, ultimately, to the lamina propria along with its constituent blood and lymph vessels as well as intrinsic and extrinsic nerve terminals. Enterocytes are characterized by their apical brush border membrane, shaped by $\sim 1000$ microvilli that cover the surface of each cell. Each microvillus is $1-2 \mu \mathrm{m}$ long and has a diameter of 100-150 nm [26], rendering a physical and functional barrier with an area of exposure of 30-40 $\mathrm{m}^{2}$ [27]. This barrier separates the intestinal lumen from the internal milieu, secreting antimicrobial peptides and restricting the passage of potentially harmful or antigenic molecules across it, while maintaining nutrient and electrolyte absorption, the transport of macromolecules, and the control of inflammation [28]. Considerable evidence now supports the existence of multidirectional communication between these layers [29].

A viscoelastic mucus gel layer with hydrophobic and surfactant properties, secreted by the goblet cells, covers the entire intestinal mucosal surface [30]. Normal mucus is totally transparent and microscopically invisible, as it is made up of more than $98 \%$ water, the rest being glycosylated proteins (mucins) and glycolipids. In the small and large intestines, mucin 2 (MUC2) is the most abundant mucus protein secreted by the goblet cells. Intestinal epithelial cells also express transmembrane mucins (MUC1, MUC3, MUC4, MUC12,
MUC13, MUC17, and MUC21) [26] that remain attached to the apical surface and form the glycocalyx together with glycolipids and are $>80 \%$ carbohydrate [30]. Secretory mucins contain cysteine-rich sequences, located in the - and C-terminal regions, which allow the formation of disulfide bridges to form large polymers that are of paramount importance for protection of the gastrointestinal tract. Recent investigations have shown that mucus is resynthesized almost two times in the colon during the average lifetime of gastrointestinal epithelial cells [31], which is the organ with the highest turnover rate in the body, estimated to be between 3 and 5 days [32]. The protein turnover of both epithelial cells and mucus in the gastrointestinal tract is coordinated by the microbiota [31]. Other components of mucus include phospholipids, while other major mucus proteins are secreted by the goblet cells, including calcium-activated-1, Fc globulin binding protein, and zymogen granule protein 16 [33], plus a variety of trefoil factors and other antimicrobials, such as secretory IgA [34], cathelicidins, lysozyme, and defensins produced by enterocytes and Paneth cells [35].

The distal colonic mucus can be divided into an outer layer, colonized by bacteria, and a mostly sterile inner layer. In the distal colon, the inner mucus layer is dense and firmly attached to the epithelium, which is approximately $50-100 \mu \mathrm{m}$ thick, with an outer layer, which is loose and movable, and about $700-800 \mu \mathrm{m}$ thick in rats and humans $[33,36,37]$. The small intestine has only one mucus layer, which is much thinner than the mucus layer in the large intestine (Fig. 2a, b). In the cecum, it seems that there are breaches in the mucus layer that may allow contact between bacteria and epithelial cells, similar to what happens in inflammatory bowel disease [38].

The mucus layer prevents adhesion and invasion by pathogenic microbes, and represents the habitat for the commensal gut bacteria that also help to limit the colonization by pathogenic microorganisms. Mucus helps to regulate gut permeability and protects the epithelial lining from luminal shear forces, the toxic effects of dietary components, various 

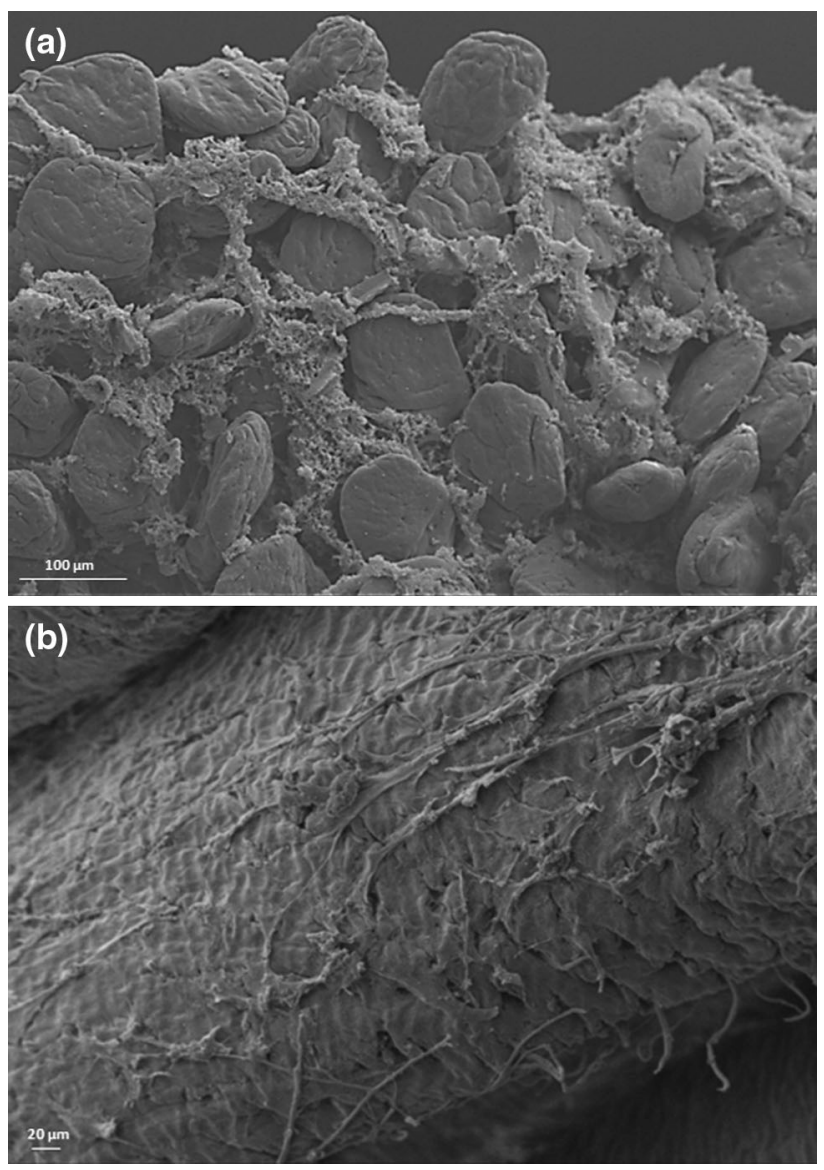

Fig. 2 Ultrastructural images of a normal mucus layer in the rat ileum and colon. a Representative electron scanning micrograph aspect of the mucus layer of the terminal ileum of an adult Wistar rat (magnification $\times 397$ ). (Courtesy

chemicals, and radiation, as well as the impact of antigens present in the intestinal lumen $[39,40]$. The mucus layer also contributes to the retention of mucosal secretions containing digestive enzymes and helps to sustain epithelial hydration [41]. Mucus seems to enhance oral tolerance by imprinting dendritic cells with anti-inflammatory properties [42], participates in epithelial renewal, differentiation, and integrity, and also interacts with other biological processes [43]. The importance of the mucus layer is reflected in studies performed in MUC2 knockout mice, in which bacteria are in direct contact with the epithelium leading to increased intestinal permeability and the spontaneous and aggravated chemically-induced development of colonic macroscopic
Dr. Maria Vicario.) b Representative electron scanning micrograph aspect of the mucus layer of the colon of an adult Wistar rat (magnification $\times 500$ ). (Courtesy Dr. Maria Vicario)

inflammation [44-46]. Similarly, in patients with active ulcerative colitis, the inner mucus layer is highly penetrable to bacteria $[45,46]$. The small intestine is more exposed to the intestinal bacteria, as the mucus layer is unattached and permeable. However, fewer microbes reside in the small intestine [47] due to the fast transit time $(0.5-5 \mathrm{~h})$ and a high concentration of antimicrobial peptides.

Just beneath the mucus layer, epithelial cells remain tightly sealed at the basolateral surface, the paracellular space, by means of the apical junctional complex [48]. This complex is composed of tight junctions (TJs), adherens junctions (AJs), and desmosomes. Three transmembrane proteins are common to all TJs: claudins, MARVEL domain proteins, and 
junctional adhesion molecules (JAMs) [49]. The claudin family consists of 26 members which regulate paracellular permeability in the gastrointestinal tract. Among claudins, claudin 2 and interleukin (IL)-13 regulate the pore pathway to form size (4-5 $\AA$ at the villus tip; $20 \AA$ at the base) and charge selective ion channels with high capacity of transport [50]. Claudin-2 expression results in increased paracellular $\mathrm{Na}^{+}$and $\mathrm{K}^{+}$conductance and water flux without any effect on $\mathrm{Cl}^{-}$conductance or paracellular flux of larger solutes, including mannitol, lactulose, and $4 \mathrm{kD}$ dextran[51]. The tightjunction-associated marvel proteins occludin, tricellulin, and marvelD3 are tetra-membrane spanning proteins that regulate the recruitment of signaling complex proteins to TJs, and cooperate in the development and regulation of macromolecular flux through the leak pathway along with zonula occludens (ZO)-1, ZO-2, and $\mathrm{ZO}-3$, and cingulin $[46,52]$. JAM-A, $-\mathrm{B}$, and $-\mathrm{C}$ are similar to immunoglobulin-G and may play important roles in barrier formation and signaling to circulating cells. AJs are located below TJs and are mainly composed of e-cadherin, catenin, and actin filaments. Alterations in intestinal permeability have been linked to the disappearance of key structural proteins of the intestinal epithelial barrier, and to be characteristic features of several chronic inflammatory disorders, including inflammatory bowel disease, celiac disease, intestinal graft versus host disease, critically ill patients, enteric infections, and infestations, human immunodeficiency virus infection, and acquired immune deficiency syndrome, IBS-D, asthma, autism, Parkinson's disease, multiple sclerosis, eczema, psoriasis, eosinophilic esophagitis, environmental enteropathy, kwashiorkor, fibromyalgia, depression, chronic fatigue syndrome, multiorgan failure syndrome (shock, burns, trauma), non-alcoholic fatty liver disease, alcoholic cirrhosis, obesity, metabolic syndrome, pancreatitis, and rheumatoid arthritis, among others [53].

When understanding the concept of lowgrade mucosal inflammation associated with disorders of chronic diarrhea, it is important to again consider the histological structure of the gut wall. The deepest layer of the intestinal barrier is the lamina propria that contains effector cells of both adaptive and innate immune systems, $\mathrm{T}$ and $\mathrm{B}$ lymphocytes, IgAsecreting plasma cells, mast cells, dendritic cells, and macrophages. The loss of epithelial integrity facilitates antigen, chemical, and toxin penetration into the lamina propria, which triggers immunological responses that, in turn, increase epithelial permeability to luminal content, thereby promoting inflammation. Indeed, several common gastrointestinal and systemic disorders associated with chronic diarrhea share alterations in the gut epithelial barrier, leading to abnormal intestinal permeability, detachment of mucous layer, intestinal dysbiosis, and, ultimately, low-grade mucosal inflammation [33, 54]. Numerous studies have provided evidence of increased numbers of immunocytes in the lamina propria of diarrheal diseases (mainly mast cells, eosinophils, and $\mathrm{T}$ cells), such as IBS-D, ulcerative colitis, or microscopic colitis [55-58].

In addition to infectious agents, there are several predisposing factors for mucus damage and intestinal leakiness that are commonly involved in the development of chronic diarrhea and mucosal inflammation. Among these, environmental stress, pregnancy, endurance exercise, drugs and antibiotics, genetic susceptibility, alcohol, and western diet, particularly dietary emulsifiers and surfactants in food additives, should be considered when evaluating and treating patients with chronic diarrhea [33, 59-64].

Therefore, agents such as mucoprotectans, due to their mucoadhesive and film-forming barrier characteristics, may offer advantages for the prevention of barrier abnormalities and restoration of the mucus layer and altered intestinal permeability to reduce mucosal inflammation and gut mucosal homeostasis.

\section{MUCOPROTECTANTS}

\section{Bismuth Subsalicylate}

BSS is an insoluble salt of salicylic acid and trivalent bismuth that was first FDA-approved in 1939 and can be considered as a mucosal 
protector with approved indications for the treatment of diarrhea, heartburn, indigestions, nausea, and stomach upset [65]. The mechanism of action is complex and partly unknown, and involves the gastric hydrolysis into bismuth, and salicylic acid [66]. The salicylate compound is almost completely absorbed into the bloodstream, while bismuth remains in the lumen of the gastrointestinal tract to form other bismuth salts [67]. These bismuth salts show bactericidal and antimicrobial activity $[66,68]$, prevent bacteria from binding and growing on the mucosal cells, inhibit intestinal secretions, promote fluid, sodium, and chloride absorption [69], reduce inflammation via cyclooxygenase inhibition [70, 71], and decrease proliferative actions of non-amidated gastrins in the rectal mucosa of Sprague-Dawley rats and mice [72], playing a major role in combating diarrhea.

\section{Xyloglugan}

$\mathrm{XG}$ is a non-ionic, water-soluble, high molecular weight branched polysaccharide hemicellulose (MW: $1331 \mathrm{Kda}$ ) [73] that carries xylose and galactosyl-xylose substituents, extracted from

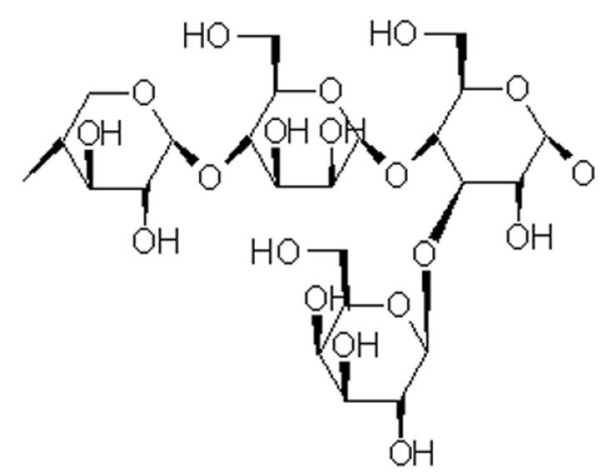

- Xylose - $B(1,4)$ - Mannose - $B(1,4)$ - Glucose - alpha(1,3) - Galactose

\section{Hemicellulose}

Fig. 3 Basic molecular structure of hemicellulose. Xyloglucan from tamarind seeds consists of four types of oligosaccharides as repeating units, commonly as heptasaccharides [155]. The monomer unit contains three types of sugars: xylose, galactose,+ and glucose. The configuration of this polysaccharide gives the product a "mucin-like" molecular structure, thus conferring optimal mucoadhesive properties [75] the most abundant source of XG and soluble fiber in nature, the seeds of the tamarind tree (Tamarindus indica) [74, 75] (Fig. 3). XG is nontoxic, edible, biocompatible, bioavailable, with versatile use in foods, and resistant to digestive enzymes, reaching the colon unaltered, where it is partially broken down to oligosaccharides by bacterial endo-ß-glucanases, followed by bacterial fermentation of oligosaccharides [76-78]. The 'mucin-like' molecular structure of XG is known to possess mucomimetic, mucoadhesive, and pseudo-plastic properties [73, 79]. In the gut, it acts as a film-forming barrier over the intestinal mucosa, helping to reduce permeability changes and invasion by pathogens like $E$. coli and to decrease cholera toxin-induced intestinal secretion in Caco2/goblet cells [80-82], preserving tight junctions [75], and binding consistently to MUC1 in molecular docking studies and decreasing the expression of MUC1 and MUC2, as shown in mice treated with dextran sodium sulfate (DSS) [73]. Both XG and GT pretreatment reduced the severity of lipopolysaccharide (LPS)/induced mucosal inflammation and jejunal hyperpermeability in male Wistar rats, although they did not prevent LPS-induced occludin and JAM-A down-regulation. Further, GT and XG limited bacterial mucus layer invasion and contact between bacteria and intestinal epithelium [83]. XG is often combined with gelatin or gelose to prolong its availability within the intestine, but showing similar protective effects as XG alone on barrier function and intestinal inflammation in rats after LPS administration [84] and Salmonella enterica and Enterococcus hirae infections [85]. In preliminary results, a single intracolonic administration combination of XG with Bifidobacterium animalis was found to be effective in inducing mucosal healing in patients with ulcerative colitis [86]. The combination of XG, pea proteins, and tannins from grape xylooligosaccharides also offered protection against stress-induced visceral hypersensitivity and intestinal hyperpermeability in rats [87]. 


\section{Gelatin Tannate}

GT is a complex of tannic acid (penta-m-digallolyl glucose) and gelatin which forms electrostatic bonds with mucin creating a proteinbased biofilm on the intestinal mucosa $[88,89]$. Gelatin is a collagen derivate, which is ingested as a powder that is insoluble at gastric acidic $\mathrm{pH}$, and which becomes a gelatin with the increase of $\mathrm{pH}$ over 5.5 [90]. This complex enters the intestine unaltered, increasing the epithelial resistance against $E$. coli infection [91], helping to restore the normal physiology of barrier function, also reducing inflammation in response to lipopolysaccharide administration in rats [92]. GT also helps to restore the mucus layer and to modulate the intestinal microbiota in the DSS-induced model of murine colitis [93], and in Caco cells [94], where it acts in part by preventing the release of intercellular adhesion molecule-1, IL-8, and tumor necrosis factor- $\alpha$ induced by LPS [95]. Furthermore, the astringent properties of tannins allow the precipitation of pro-inflammatory molecules from the intestinal mucus and their fecal elimination $[96,97]$. Together, these effects may explain, at least in part, the protective effect of GT on intestinal barrier function.

\section{Dioctahedral Smectite or Diosmectite}

Diosmectite (DS) is a medicinal clay and a product frequently recommended over-the-counter in Eastern European countries [98], France [99], and China [100] as an adjuvant therapy in children and adults with acute diarrhea. It is administered to reduce stool output, providing symptomatic relief, and possibly preventing dehydration [101]. It is formed from sheets of aluminum and magnesium silicate. The mechanism of action is thought to be the result of: anti-inflammatory activity; modifications of the rheological characteristics of the gastrointestinal mucus barrier to reduce penetration of toxins and adsorptive properties; reduction of intestinal permeability and apoptosis; and improved intestinal epithelial cells proliferation, via modulation of IL-8, transforming growth factor, extracellular signal-regulated kinase $1 / 2$, and protein kinase B signaling pathway, and MUC2 expression [102, 103], thereby reducing stool output and stress-induced visceral hypersensitivity. These mechanisms have been replicated, mainly in vitro, in Caco- 2 and HT-29 cell lines, and in vivo in rodent and piglets animal models [104-109], and the results may be improved by combination with Lactobacillus acidophilus [110].

\section{METHODS}

We searched MEDLINE and EMBASE via OVID, from 1977 to January 2021 using a combination of MeSH terms, EMTREE terms, and keywords developed for each database. We also conducted a search for all English language articles, systematic reviews, meta-analysis, conference proceedings, and abstracts in relevant scientific meetings, on the epidemiology, etiology, physiopathology, and management of chronic and persistent diarrhea in immunocompetent individuals using the search terms: persistent diarrhea, chronic diarrhea, infectious diarrhea, enteric infection, epidemiology, treatment, management, guidelines, adults, mucus, intestinal permeability, xyloglucan, gelatin tannate, bismuth subsalicylate, diosmectite, smectite, and mucoprotectans. Bibliographies of review and meta-analysis articles were used to identify additional sources. Websites for the US Centers for Disease Control and Prevention, US Food and Drug Administration, and World Health Organization were also accessed for any additional information related to this topic.

All studies were reviewed and summarized by two independent reviewers to determine their eligibility. Only primary studies conducted on human adult subjects (18 years and older) presenting with chronic diarrhea with observed parameters directly related to diarrhea were included.

This article is based on previously conducted studies and does not contain any new studies with human participants or animals performed by any of the authors. 


\section{RESULTS}

Available studies were read and summarized, and the study design, population, parameters observed, and outcomes documented (Table 1).

\section{BSS in Chronic/Persistent Diarrhea in Adults}

Chronic/persistent diarrhea occurs in approximately $3 \%$ of individuals traveling to developing countries, and in more than $10 \%$ of patients suffering acute infectious enteritis [111]. The microbiologic causes include parasitic (e.g., Giardia, Cryptosporidium, Schistosoma mansoni) and bacterial (e.g., enteroaggregative E. coli, Shigella, Campylobacter, Salmonella) pathogens [21]. BSS has demonstrated effectiveness in the prevention of traveler's diarrhea $[112,113]$ and in the treatment of acute diarrhea [114]. For traveler's diarrhea in adult patients with mild symptoms $[115,116]$, BSS has been shown to decrease stool frequency, time to symptom relief, need for intravenous rehydration, and work absenteeism in comparison to placebo or antibiotics. However, there are no studies on the effect of BSS on chronic/persistent diarrhea after acute infectious enteritis. Considering the efficacy of BSS in the management of acute diarrhea and the increasing prevalence of postinfective diarrhea and antibiotic resistance among diarrheal pathogens [117], it would be wise to perform additional studies to evaluate the efficacy and safety of BSS in the management of postinfective diarrhea.

Both IBS-D and microscopic colitis (MC) are common causes of chronic diarrhea in adults. One open-label study showed that the combination of BSS and spasmolytics during 3 weeks improved bowel symptoms in IBS-D, including diarrhea in a small group of patients $(n=20)$ [118]. BSS is recommended by the 2016 AGA guideline as a second-line therapy for $\mathrm{MC}$ when budesonide is unable to be used, either due to cost or adverse effects [119]. This is based on two small studies that found that treatment with BSS for 8 weeks reduced the frequency and weight of bowel movements, improved stool consistency, and decreased tissue inflammation in patients with MC $[120,121]$. A retrospective study showed complete response in 53\% of patients and partial response in $28 \%$ of patients taking three tablets (262 mg each) of bismuth salicylate three times a day [122]. Chronic diarrhea is a common manifestation of a variety of cancers that can be attributed to adverse effects of treatments, radiotherapy, surgery, and infection. One prospective pilot study revealed that the duration of diarrhea experienced by lymphoma patients receiving melphalan chemotherapy was decreased as compared to the placebo group, while this did not happen in multiple myeloma patients irrespective of treatment [123]. However, this article has been retracted by the journal because major findings could not be replicated upon reanalysis [124]. Though anecdotical, a recent case report showed a good temporal response of diarrhea in a COVID-19-positive Crohn's disease patient treated with BSS [125].

Limitation to its use in chronic diarrhea relate to the number of daily tablets needed to treat, to the compromised absorption of other compounds and to the restricted use in patients with renal impairment [126]. BSS is safe, relatively cheap, and has limited side effects, yet tinnitus, blackened tongue and dark feces are not unusual in short-term therapy and make its use undesirable for some patients [124]. Although quite rare, the most concerning adverse effect of BSS is salicylate and bismuth non-eurotoxicity that primarily occurs in patients who have taken bismuth subsalicylate inappropriately, whether through an overdose or for extended periods of time [127].

\section{XG in Chronic/Persistent Diarrhea in Adults}

Several clinical trials have been reported on the efficacy of XG in the treatment of acute diarrhea in children [128, 129] and adults [81]. However, there are limited data regarding its use in chronic diarrhea. One recent multicenter, double-blind, placebo-controlled, randomized, crossover clinical trial evaluated the efficacy and safety of a commercially available combination of $X G$, pea protein, and tannins from 


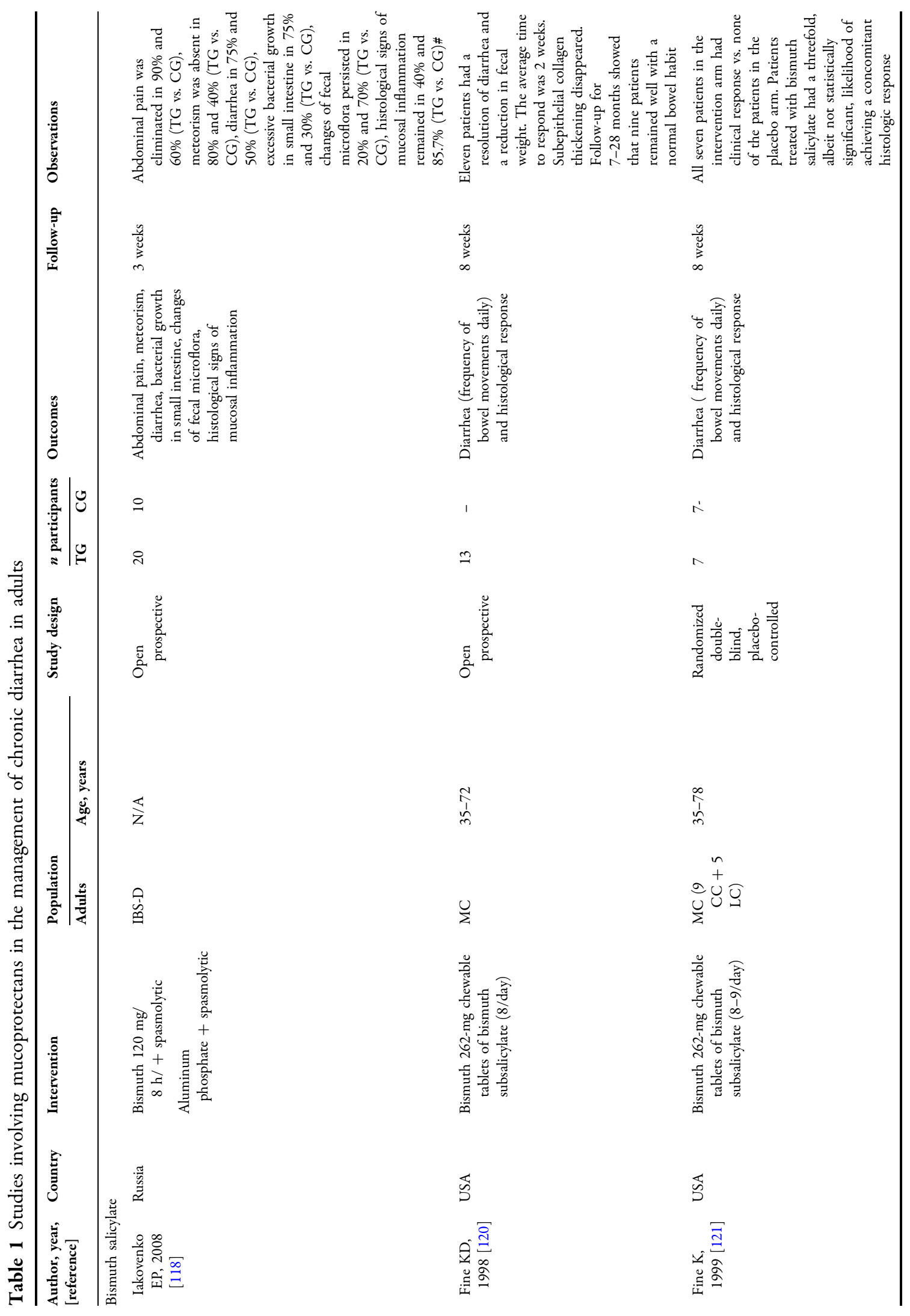




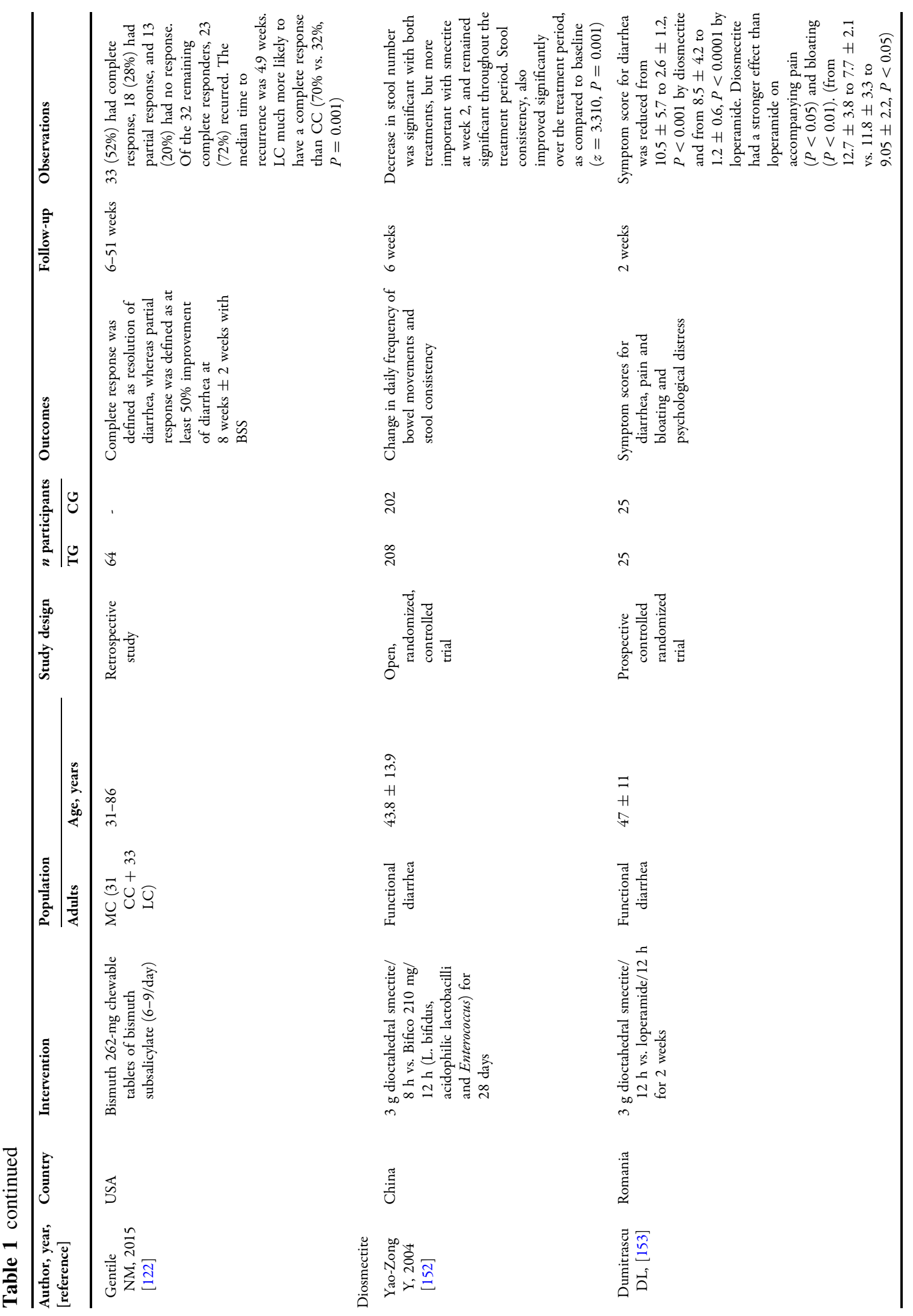




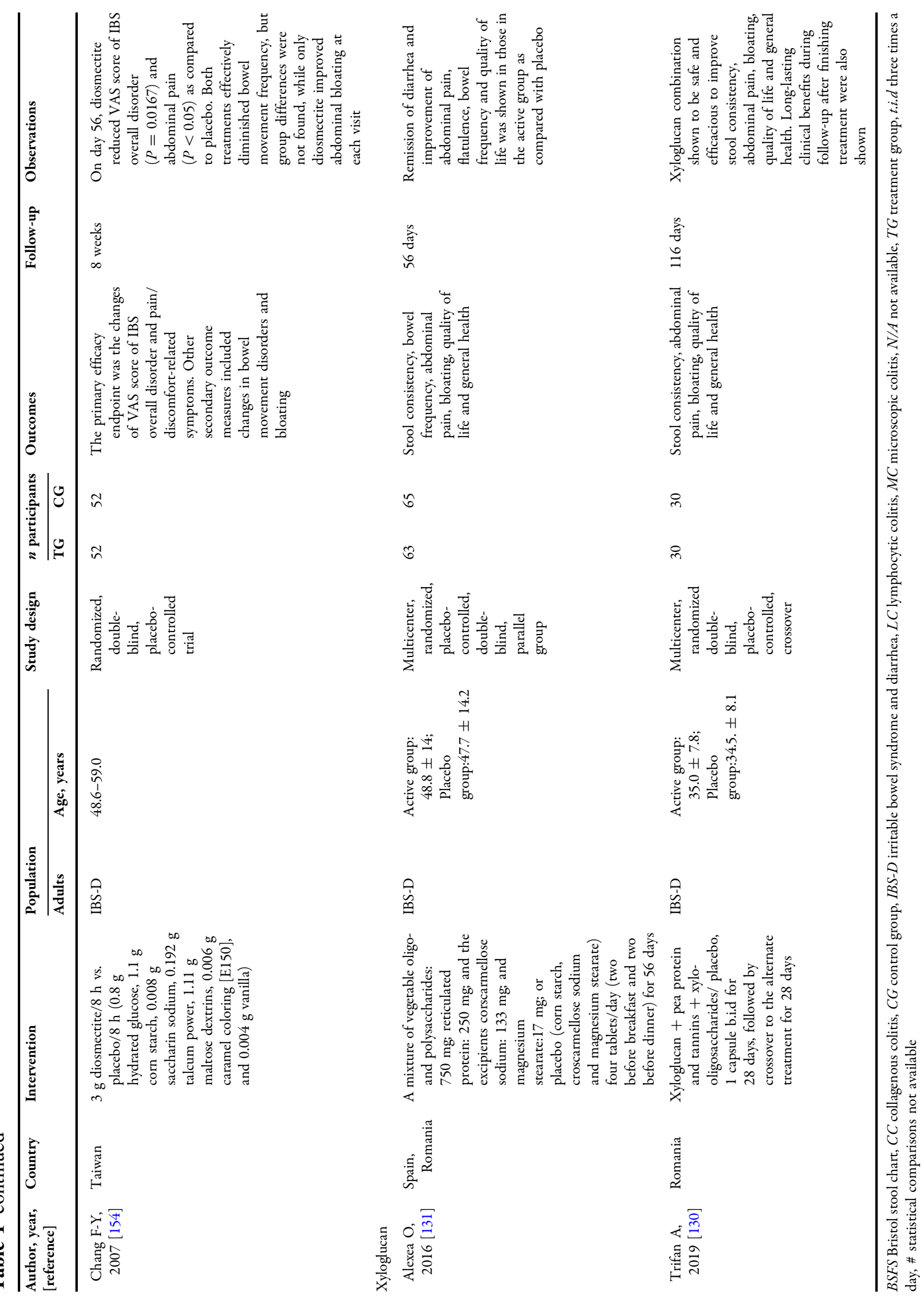


grape seed extract, and xylo-oligosaccharides in patients with IBS-D [130]. The study showed that, at day 28, the therapeutic combination of XG normalized stool consistency in a significantly higher proportion of patients as compared to placebo (87 vs. $0 \% ; P=0.0019$ ), and, after the crossover, at day 56 , the effect of XG was reproduced $(93 \%$ vs. $23 \% ; P=0.0001)$. This benefit remained present at day 116 of followup $(67 \%$ vs. $13 \%)$ with no significant adverse events. In most cases, remission of diarrhea symptoms was apparent within 15 days of starting treatment. A therapeutic gain was also observed for abdominal pain and bloating.

Another study assessed other precursor medical device containing other film-forming agents, reticulated proteins, in combination with a prebiotic mixture of vegetable oligo- and poly-saccharides, in patients with IBS-D [131]. After 8 weeks of treatment, remission of diarrhea, defined as two or less non-watery stools emissions per day (stool of type 5 or less on the BSFS) was achieved in $76.19 \%$ in the active group vs. $47.69 \%$ in the placebo group $(P<0.0001)$. In addition, bowel frequency $(P=0.001)$, abdominal pain $(P=0.0167)$, and flatulence $(P=0.0373)$ were all significantly improved in patients in the active group as compared with placebo at 56 days of follow-up. A significant increase in the quality of life was also detected in the active group at day 56 $(P<0.0001$ vs. placebo $)$. No major adverse events were recorded and treatment was well tolerated.

In conjunction, these results support the use of the use of XG reticulated protein and oligoand polysaccharides in the treatment of chronic diarrhea, at least in IBS-D patients.

\section{GT in Chronic/Persistent Diarrhea in Adults}

Similar to $X G$, several clinical trials have been reported on the use of GT in the treatment of acute diarrhea in children [90, 132-138], and adults $[139,140]$, with conflictive results on the efficacy as published in three different metaanalysis [24, 141, 142]. Unfortunately, we have not found studies with GT in adult patients with chronic diarrhea. Although, the combination of GT and tyndallized probiotics has been claimed as highly effective in the treatment of moderate and prolonged diarrhea [143, 144], there is so far no clinical evidence to support this. However, a randomized, double-blinded, placebo-controlled, clinical trial investigating the efficacy and safety of gelatin tannate and tyndallized acid lactic bacteria versus placebo administered to adult patients with chronic diarrhea with dysbiosis is ongoing (ISRCTN63068134).

\section{DS in Chronic/Persistent Diarrhea in Adults}

The potential utility of DS in the management of chronic diarrhea is based on its efficacy as shown in a number of open [145-147] and randomized double-blind, placebo-controlled [104, 148-151] clinical trials performed mostly in children with acute diarrhea, and highlighted in a recent Cochrane review [101]. One open, randomized, controlled trial compared the efficacy of $3 \mathrm{~g}$ of dioctahedral smectite $/ 8 \mathrm{~h}$ versus a commercial mixture of probiotics containing $L$. bifidus, acidophilic lactobacilli and Enterococcus in the management of chronic functional diarrhea in a large group of participants, during 28 consecutive days [152]. As soon as 2 weeks from the beginning of treatment, smectite was shown to be significantly superior to probiotics in reducing bowel frequency $(P=0.007)$, and this gain was maintained over the treatment period and during the follow-up period of 2 weeks. A similar significant benefit for smectite over probiotics was shown for stool consistency at 2 weeks of treatment and remained for the 28 days $(P=0.001)$, but the benefit disappeared after discontinuation. No serious adverse effects were reported. Another prospective controlled randomized trial study compared DS against loperamide for 2 weeks in the management of chronic functional diarrhea. This study showed a similar efficacy of both drugs for the control of diarrhea while DS was superior to loperamide in the control of pain and bloating [153]. Another randomized, double-blind, placebo-controlled 
trial, showed no benefit of DS over placebo in improving bowel frequency, consistency, urgency and mucus discharge in IBS-D after 8 weeks of treatment [154]. However, DS significantly improved abdominal pain, bloating, and the overall visual analogue scale score of IBS. No serious adverse effects were reported. However, three patients were hospitalized during the trial (two in the placebo group because of cellulitis and acute appendicitis; one in the DS group because of renal stone). Constipation was the most common effect related to DS treatment, but its occurrence was not different from placebo. Other recorded adverse effects were similar in both groups: nausea, abdominal pain, and dyspepsia.

\section{SUMMARY AND CONCLUSIONS}

There are many available drugs for the treatment of chronic diarrhea. The majority of them target specific mechanisms/pathways involved in the origin of diarrhea. However, it is common for many disorders associated with chronic diarrhea, particularly (but not only) for the very prevalent IBS-D and functional diarrhea, that their development involves multiple or unidentified mechanisms. Among these mechanisms, the impairment of the intestinal barrier with changes in epithelial permeability, mucus layer, and immune activation deserves special focus because they have been increasingly implicated in the initiation and perpetuation of a variety of diseases, thereby justifying the emerging interest in the advent of new pharmacological/non-pharmacological approaches for the restoration of barrier function.

Much of this work relates to the use of mucosal protectors, as a new alternative or complementary therapy for a more efficient and safe control of symptoms in disorders associated with chronic diarrhea, mostly in IBS-D. The objective of mucosal protection is to create an artificial mechanical barrier over the mucosa, to reduce contact/access between noxious allergens, irritants, toxins, pathogens, and their virulence factors and the mucosal immune system, to prevent mucus damage and preserve intestinal permeability. The need of these barrier enhancers, some marketed as medical devices, is also supported in the current context of high levels of antimicrobial resistance and to avoid long-lasting pharmacological treatments, their adverse events, and frequent elevated costs. In adults with chronic diarrhea, the studies available to date suggest that these mucoprotectants can be helpful, improving stool frequency and consistency, and showing beneficial effects on other symptoms such as abdominal pain, bloating, and flatulence. Importantly, they appear to be safe, with few adverse events, although some caution is advised on the chronic use of BSS and tannins and on their potential interference with the mechanism of action of other drugs. In addition, it is currently unclear whether the use of mucoprotectans is cost-effective, partly because some of them (xyloglucan, gelatin tannate, and disomectite) are sold over the counter and not covered by health insurance or public health systems, and partly because the lack of highquality evidence. However, there are a number of limitations to the available data. There is a paucity of studies and several of them have been criticized because they were reported only as abstracts or posters, and many were observational in design and did not include a control group, rendering a low quality of evidence due to imprecision, inconsistency, and risk of bias when defining diarrhea characteristics across studies, yet this criticism may be limited due to heterogeneity in some outcomes [142]. In addition, the evidence provided relates mostly to IBS-D, which may not be applicable to other disorders with chronic diarrhea. Finally, it is important to note here that, while some of these products are marketed as mucoprotectans, the mechanism by which they protect the mucosa is not well established, just as it is not well established that mucoprotection is the mechanism by which chronic diarrhea is ameliorated. In conclusion, although mucoprotectans are promising, there is a clear need for additional randomized controlled trials in large and controlled populations assessing clinically relevant outcomes to further explore their effects and confirm their usefulness in the treatment of chronic diarrhea. Microbiological analysis of fecal and mucosal samples would 
also provide useful information about their effects on intestinal microbiota, particularly in patients with dysbiosis. In addition, clinical, functional, and laboratory evaluation of their effects on intestinal permeability and mucus integrity is also warranted to ascertain their in vivo ability to restore these functions and to extend their use in the management of a variety of gastrointestinal diseases associated with 'leaky gut.'

\section{ACKNOWLEDGEMENTS}

Funding. Supported in part by Fondo Europeo de Desarrollo Regional (FEDER), Fondo de Investigación Sanitaria and Centro de Investigación Biomédica en Red de Enfermedades Hepáticas y Digestivas (CIBEREHD), Instituto de Salud Carlos III, Subdirección General de Investigación Sanitaria, Ministerio de Economía y Competitividad, Ajuts per a la contractació de personal investigador FI-Agència de Gestió d'Ajuts Universitaris i de Recerca (AGAUR), Generalitat de Catalunya, The Swedish Research Council and The European Commision: FIS LOBO 2019? (BL); FI20/00256 (MA-B). PI17/ 0190 (JS); PI15/00301 (CA-C); CIBERehd CB06/ 04/0021 (JS \& CA-C); dnr 2019-00653 (J-PGM); 2020FI_B1 00127, 2019FI_B 00817 (MA-B); GA No:848228 (JS, CA-C, EE, AMG-C, BL). No funding or sponsorship was received for the publication of this article.

Authorship. All named authors meet the International Committee of Medical Journal Editors (ICMJE) criteria for authorship for this article, take responsibility for the integrity of the work as a whole, and have given their approval for this version to be published.

Authorship Contributions. MA-G, BL, AMGC, MA-B, J-PGM, EE and CA-C reviewed scientific literature and collected data; $\mathrm{CA}-\mathrm{C}, \mathrm{BL} \& \mathrm{JS}$ wrote the paper; MA-G, BL, MA-G, AMG-C, MA-B, EE and J-PGM prepared the tables and figures; All authors critically reviewed and edited the manuscript in its final version. All authors approved the final draft of the manuscript.
Disclosures. Mar Abril-Gil, Beatriz Lobo, Mercé Albert-Bayo, John Peter Ganda-Mall, Ana María González-Castro have nothing to disclose. Carmen Alonso-Cotoner discloses past scientific collaborations with Noventure S.L. Javier Santos has served as consultant for Noventure and discloses present and past recent scientific collaborations with Salvat, Norgine, Alfa-Sigma, Cosmo, Adare, Devintecpharma, Pileje and Danone.

Compliance with Ethics Guidelines. This article is based on previously conducted studies and does not contain any new studies with human participants or animals performed by any of the authors.

Open Access. This article is licensed under a Creative Commons Attribution-NonCommercial 4.0 International License, which permits any non-commercial use, sharing, adaptation, distribution and reproduction in any medium or format, as long as you give appropriate credit to the original author(s) and the source, provide a link to the Creative Commons licence, and indicate if changes were made. The images or other third party material in this article are included in the article's Creative Commons licence, unless indicated otherwise in a credit line to the material. If material is not included in the article's Creative Commons licence and your intended use is not permitted by statutory regulation or exceeds the permitted use, you will need to obtain permission directly from the copyright holder. To view a copy of this licence, visit http://creativecommons.org/licenses/by$\mathrm{nc} / 4.0 /$.

\section{REFERENCES}

1. Schiller LR, Pardi DS, Spiller R, et al. Gastro 2013 APDW/WCOG Shanghai working party report: chronic diarrhea: definition, classification, diagnosis. J Gastroenterol Hepatol. 2014;29:6-25.

2. Schiller LR. Evaluation of chronic diarrhea and irritable bowel syndrome with diarrhea in adults in the era of precision medicine. Am J Gastroenterol. 2018;113:660-9. 
3. Sandler RS, Everhart JE, Donowitz M, et al. The burden of selected digestive diseases in the United States. Gastroenterology. 2002;122:1500-11.

4. Peery AF, Dellon ES, Lund J, et al. Burden of gastrointestinal disease in the United States: 2012 update. Gastroenterology. 2012;143(1179-1187):e3.

5. GBD 2019 Diseases and Injuries Collaborators. Global burden of 369 diseases and injuries in 204 countries and territories, 1990-2019: a systematic analysis for the Global Burden of Disease Study 2019. Lancet. 2020;396(10258):1204-22.

6. Wenzl HH, Fine KD, Schiller LR, et al. Determinants of decreased fecal consistency in patients with diarrhea. Gastroenterology. 1995;108:1729-38.

7. Fine KD, Schiller L. AGA technical review on the evaluation and management of chronic diarrhea. Gastroenterology. 1999;116:1464-86.

8. Shane AL, Mody RK, Crump JA, et al. 2017 Infectious Diseases Society of America Clinical Practice Guidelines for the Diagnosis and Management of Infectious Diarrhea. Clin Infect Dis. 2017;65: e45-80.

9. Descoteaux-Friday GJ, Shrimanker I. Chronic Diarrhea. [Updated 2020 Nov 17]. In: StatPearls [Internet]. Treasure Island (FL): StatPearls Publishing; 2020. https://www.ncbi.nlm.nih.gov/books/ NBK544337/. Accessed 13 Mar 2021.

10. Lewis SJ, Heaton KW. Stool form scale as a useful guide to intestinal transit time. Scand J Gastroenterol. 1997;32:920-4.

11. O'Donnell LJ, Virjee J, Heaton KW. Detection of pseudodiarrhoea by simple clinical assessment of intestinal transit rate. BMJ. 1990;300:439-40.

12. Arasaradnam RP, Brown S, Forbes A, et al. Guidelines for the investigation of chronic diarrhoea in adults: British Society of Gastroenterology, 3rd edition. Gut. 2018;67:1380-99.

13. Talley NJ, Weaver AL, Zinsmeister AR, et al. Onset and disappearance of gastrointestinal symptoms and functional gastrointestinal disorders. Am J Epidemiol. 1992;136:165-77.

14. Zhao Y-F, Guo X-J, Zhang Z-S, et al. Epidemiology of functional diarrhea and comparison with diarrheapredominant irritable bowel syndrome: a population-based survey in China. PLoS One. 2012;7: e43749.

15. Fosnes GS, Lydersen S, Farup PG. Constipation and diarrhea-common adverse drug reactions? A cross sectional study in the general population. BMC Clin Pharmacol. 2011;11:2.
16. Thompson WG, Irvine EJ, Pare $P$, et al. Functional gastrointestinal disorders in Canada: first population-based survey using Rome II criteria with suggestions for improving the questionnaire. Dig Dis Sci. 2002;47:225-35.

17. Singh P, Mitsuhashi S, Ballou S, et al. Demographic and Dietary Associations of Chronic Diarrhea in a Representative Sample of Adults in the United States. Am J Gastroenterol. 2018;113:593-600.

18. Sperber AD, Bangdiwala SI, Drossman DA, et al. Worldwide prevalence and burden of functional gastrointestinal disorders, results of Rome Foundation Global Study. Gastroenterology. 2021;160(1): 99-114.e3.

19. Thomas PD, Forbes A, Green J, et al. Guidelines for the investigation of chronic diarrhoea, 2nd edition. Gut. 2003;52(Suppl 5):v1-15.

20. Fernández-Bañares F, Accarino A, Balboa A, et al. Diarrea crónica: definición, clasificación y diagnóstico [Chronic diarrhoea: Definition, classification and diagnosis]. Gastroenterol Hepatol. 2016;39:535-59.

21. DuPont HL. Persistent diarrhea: a clinical review. JAMA. 2016;315:271223.

22. Schiller LR, Pardi DS, Sellin JH. Chronic diarrhea: diagnosis and management. Clin Gastroenterol Hepatol. 2017;15(182-193):e3.

23. Schiller LR. Antidiarrheal drug therapy. Curr Gastroenterol Rep. 2017;19:18.

24. Aloi M, Mennini M. Efficacy of gelatin tannate for acute diarrhea in children: a systematic review and meta-analysis. J Comp Eff Res. 2019;8:91-102.

25. Eutamene H, Beaufrand C, Harkat C, et al. The role of mucoprotectants in the management of gastrointestinal disorders. Expert Rev Gastroenterol Hepatol. 2018;12:83-90.

26. Pelaseyed T, Hansson GC. Membrane mucins of the intestine at a glance. J Cell Sci. 2020;133(5): jcs 240929.

27. Helander HF, Fändriks L. Surface area of the digestive tract-revisited. Scand J Gastroenterol. 2014;49: 681-9.

28. Wood JD. Neuropathophysiology of functional gastrointestinal disorders. World J Gastroenterol. 2007;13:1313-32.

29. Sansonetti PJ. War and peace at mucosal surfaces. Nat Rev Immunol. 2004;4:953-64. 
30. Johansson ME, Sjovall H, Hansson GC. The gastrointestinal mucus system in health and disease. Nat Rev Gastroenterol Hepatol. 2013;10:352-61.

31. Arike L, Seiman A, van der Post S, et al. Protein turnover in epithelial cells and mucus along the gastrointestinal tract is coordinated by the spatial location and microbiota. Cell Rep. 2020;30(1077-1087):e3.

32. Creamer B, Shorter RG, Bamforth J. The turnover and shedding of epithelial cells. I. The turnover in the gastro-intestinal tract. Gut. 1961;2:110-8.

33. Camilleri M. Leaky gut: mechanisms, measurement and clinical implications in humans. Gut. 2019;68: 1516-26.

34. Brandtzaeg P. Molecular and cellular aspects of the secretory immunoglobulin system. APMIS. 1995;103:1-19.

35. Bevins CL, Salzman NH. Paneth cells, antimicrobial peptides and maintenance of intestinal homeostasis. Nat Rev Microbiol. 2011;9:356-68.

36. Atuma C, Strugala V, Allen A, et al. The adherent gastrointestinal mucus gel layer: thickness and physical state in vivo. Am J Physiol Gastrointest Liver Physiol. 2001;280:G922-9.

37. Johansson ME, Phillipson M, Petersson J, et al. The inner of the two Muc2 mucin-dependent mucus layers in colon is devoid of bacteria. Proc Natl Acad Sci USA. 2008;105:15064-9.

38. Furter M, Sellin ME, Hansson GC, et al. Mucus architecture and near-surface swimming affect distinct salmonella typhimurium infection patterns along the murine intestinal tract. Cell Rep. 2019;27(2665-2678):e3.

39. Gibson P, Rosella O, Nov R, et al. Colonic epithelium is diffusely abnormal in ulcerative colitis and colorectal cancer. Gut. 1995;36:857-63.

40. Qin X, Caputo FJ, Xu DZ, et al. Hydrophobicity of mucosal surface and its relationship to gut barrier function. Shock. 2008;29:372-6.

41. Lievin-Le Moal V, Servin AL. The front line of enteric host defense against unwelcome intrusion of harmful microorganisms: mucins, antimicrobial peptides, and microbiota. Clin Microbiol Rev. 2006;19:315-37.

42. Shan M, Gentile M, Yeiser JR, et al. Mucus enhances gut homeostasis and oral tolerance by delivering immunoregulatory signals. Science. 2013;342: 44753.
43. Corfield AP, Carroll D, Myerscough N, et al. Mucins in the gastrointestinal tract in health and disease. Front Biosci. 2001;6:D1321-57.

44. Van der Sluis M, De Koning BA, De Bruijn AC, et al. Muc2-deficient mice spontaneously develop colitis, indicating that MUC2 is critical for colonic protection. Gastroenterology. 2006;131:117-29.

45. Johansson ME, Gustafsson JK, Holmén-Larsson J, et al. Bacteria penetrate the normally impenetrable inner colon mucus layer in both murine colitis models and patients with ulcerative colitis. Gut. 2014;63:281-91.

46. Wenzel UA, Magnusson MK, Rydström A, et al. Spontaneous colitis in Muc2-deficient mice reflects clinical and cellular features of active ulcerative colitis. PLoS One. 2014;9:e100217.

47. O'Hara AM, Shanahan F. The gut flora as a forgotten organ. EMBO Rep. 2006;7(7):688-93.

48. Farquhar MG, Palade GE. Junctional complexes in various epithelia. J Cell Biol. 1963;17:375-412.

49. Zihni C, Mills C, Matter K, et al. Tight junctions: from simple barriers to multifunctional molecular gates. Nat Rev Mol Cell Biol. 2016;17:564-80.

50. Lingaraju A, Long TM, Wang Y, et al. Conceptual barriers to understanding physical barriers. Semin Cell Dev Biol. 2015;42:13-21.

51. Rosenthal R, Günzel D, Theune D, et al. Water channels and barriers formed by claudins. Ann N Y Acad Sci. 2017;1397:100-9.

52. Cording J, Berg J, Käding N, et al. In tight junctions, claudins regulate the interactions between occludin, tricellulin and marvelD3, which, inversely, modulate claudin oligomerization. J Cell Sci. 2013;126(Pt 2):554-64.

53. Arrieta MC, Bistritz L, Meddings JB. Alterations in intestinal permeability. Gut. 2006;55:1512-20.

54. Thaiss CA, Levy M, Grosheva I, et al. Hyperglycemia drives intestinal barrier dysfunction and risk for enteric infection. Science. 2018;359(6382): 13761383.

55. González-Castro AM, Martínez C, Salvo-Romero E, et al. Mucosal pathobiology and molecular signature of epithelial barrier dysfunction in the small intestine in irritable bowel syndrome. J Gastroenterol Hepatol. 2017;32:5363.

56. Cremon C, Gargano L, Morselli-Labate AM, et al. Mucosal immune activation in irritable bowel syndrome: gender-dependence and association with 
digestive symptoms. Am J Gastroenterol. 2009;104: 392-400.

57. Bashashati M, Moossavi S, Cremon C, et al. Colonic immune cells in irritable bowel syndrome: a systematic review and meta-analysis. Neurogastroenterol Motil. 2018;30(1):e13192.

58. Wouters MM, Vicario M, Santos J. The role of mast cells in functional GI disorders. Gut. 2016;65: 155-68.

59. He J, Guo H, Zheng W, et al. Effects of stress on the mucus-microbial interactions in the gut. Curr Protein Pept Sci. 2019;20:155-63.

60. Da Silva S, Robbe-Masselot C, Ait-Belgnaoui A, et al. Stress disrupts intestinal mucus barrier in rats via mucin O-glycosylation shift: prevention by a probiotic treatment. Am J Physiol Gastrointest Liver Physiol. 2014;307:G420-9.

61. Alonso C, Guilarte M, Vicario M, et al. Maladaptive intestinal epithelial responses to life stress may predispose healthy women to gut mucosal inflammation. Gastroenterology. 2008;135(163-172):e1.

62. Pals KL, Chang RT, Ryan AJ, et al. Effect of running intensity on intestinal permeability. J Appl Physiol (1985). 1997;82:571-6.

63. Partridge D, Lloyd KA, Rhodes JM, et al. Food additives: assessing the impact of exposure to permitted emulsifiers on bowel and metabolic healthintroducing the FADiets study. Nutr Bull. 2019;44: $329-49$.

64. Chelakkot C, Ghim J, Ryu SH. Mechanisms regulating intestinal barrier integrity and its pathological implications. Exp Mol Med. 2018;50:103.

65. Budisak P, Abbas M. Bismuth Subsalicylate. 2020 Nov 26. In: StatPearls [Internet]. Treasure Island (FL): StatPearls Publishing; 2020. PMID: 32809532.

66. Pitz AM, Park GW, Lee D, et al. Antimicrobial activity of bismuth subsalicylate on Clostridium difficile, Escherichia coli O157:H7, norovirus, and other common enteric pathogens. Gut Microbes. 2015;6:93-100.

67. Nwokolo CU, Mistry P, Pounder RE. The absorption of bismuth and salicylate from oral doses of PeptoBismol (bismuth salicylate). Aliment Pharmacol Ther 1990;4:163-9.

68. Manhart MD. In vitro antimicrobial activity of bismuth subsalicylate and other bismuth salts. Rev Infect Dis. 1990;12(Suppl 1):S11-5.

69. Gorbach SL. Bismuth therapy in gastrointestinal diseases. Gastroenterology. 1990;99:863-75.
70. National Center for Biotechnology Information (2021). PubChem Compound Summary for CID 16682734, Bismuth subsalicylate. Retrieved January 5, 2021 from https://pubchem.ncbi.nlm.nih.gov/ compound/Bismuth-subsalicylate. Accessed 13 Mar 2021.

71. Sheele J, Cartowski J, Dart A, et al. Saccharomyces boulardii and bismuth subsalicylate as low-cost interventions to reduce the duration and severity of cholera. Pathog Glob Health. 2015;109:275-82.

72. Kovac S, Loh SW, Lachal S, et al. Bismuth ions inhibit the biological activity of non-amidated gastrins in vivo. Biochem Pharmacol. 2012;83: 524-30.

73. Periasamy S, Lin $\mathrm{CH}$, Nagarajan B, et al. Mucoadhesive role of tamarind xyloglucan on inflammation attenuates ulcerative colitis. J Funct Foods. 2018;47:1-10.

74. Kozioł A, Cybulska J, Pieczywek PM, et al. Evaluation of structure and assembly of xyloglucan from tamarind seed (Tamarindus indica L.) with atomic force microscopy. Food Biophys. 2015;10:396-402.

75. Piqué N, Gómez-Guillén MDC, Montero MP. Xyloglucan, a plant polymer with barrier protective properties over the mucous membranes: an overview. Int J Mol Sci. 2018;19:673.

76. Misrha A, Malhotra AV. Tamarind xyloglucan: a polysaccharide with versatile application potential. J Mater Chem. 2009;19:85288536.

77. Sone Y, Makino C, Misaki A. Inhibitory effect of oligosaccharides derived from plant xyloglucan on intestinal glucose absorption in rat. J Nutr Sci Vitaminol (Tokyo). 1992;38:391-5.

78. Hartemink R, Van Laere KMJ, Mertens AKC, et al. Fermentation of xyloglucan by intestinal bacteria. Anaerobe. 1996;2:223-30.

79. Mannucci LL, Fregona I, Di Gennaro A. Use of a new lachrymal substitute (T S Polysaccharide) in contactology. J Med Contactology Low Vis. 2000;1:6-9.

80. Bueno L, Theodoru V, Sekkal S. Xyloglucan: a new agent to protect the intestinal mucosa and to prevent bacterially-mediated alteration of tight junction permeability. United Eur Gastroenterol J. 2014;2(Suppl 1):A592(P1675).

81. Gnessi L, Bacarea V, Marusteri M, et al. Xyloglucan for the treatment of acute diarrhea: results of a randomized, controlled, open-label, parallel group, multicentre, national clinical trial. BMC Gastroenterol. $2015 ; 15: 153$. 
82. de Servi B, Ranzini F, Piqué N. Effect of Utipro( $\left({ }^{\circledR}\right)$ (containing gelatin-xyloglucan) against Escherichia coli invasion of intestinal epithelial cells: results of an in vitro study. Future Microbiol. 2016;11:651-8.

83. Eutamene H. Undissociated gelatine tannate and xyloglucan prevent gut leakiness and mucosal inflammation induced by LPS: insights in the mechanism of action. United Eur Gastroenterol J. 2016;4(5S):A651(P1449).

84. Eutamene H, Harkat C, Theodoru V. Comparative effect of xyloglycan associations with compounds from animal or algae origin on LPS-induced enteritis in rats. United Eur Gastroenterol J. 2017;5(5S): A311(P0419).

85. Esposito E, Campolo M, Casili G, et al. Protective effects of xyloglucan in association with the polysaccharide gelose in an experimental model of gastroenteritis and urinary tract infections. Int J Mol Sci. 2018;19:1844.

86. Bozkurt HS, Kara B. A new treatment for ulcerative colitis: Intracolonic Bifidobacterium and xyloglucan application. Eur J Inflamm. 2020;18:1-7.

87. Eutamene H, Placide F, Tondereau V, et al. Protective effect of mucoprotectants and prebiotic combination on gut barrier impairment and visceral hypersensitivity induced by an acute stress in rat. Gastroenterology. 2018;154(Suppl 1):S916: (TU1254).

88. Freli V, da Silva RM, Pescio P. New insights into the mechanism of action of gelatine tannate for acute diarrhoea. Part 1: film-forming effect [Abstract]. Arch Pediatr. 2013;20:549.

89. Lopetuso LR, Scaldaferri F, Bruno G, et al. The therapeutic management of gut barrier leaking: the emerging role for mucosal barrier protectors. Eur Rev Med Pharmacol Sci. 2015;19:1068-76.

90. Esteban Carretero J, Durban Reguera F, Lopez-Argueta Alvarez S, et al. A comparative analysis of response to vs. ORS + gelatin tannate pediatric patients with acute diarrhea. Rev Esp Enferm Dig. 2009;101:41-8.

91. Servi B, Ranzini F. Protective efficacy of antidiarrheal agents in a permeability model of Escherichia coli-infected CacoGoblet ${ }^{\circledR}$ cells. Future Microbiol. 2017;12:1449-55.

92. Bueno L, Sekkal S, Theodorou V, et al. Undissociated gelatin tannate reduces intestinal leakiness and mucosa inflammation by forming a protective biofilm: results from in-vitro and in-vivo studies. United Eur Gastroenterol J. 2013;1(1 suppl):A75-6 (OP249).
93. Scaldaferri F, Lopetuso LR, Petito V, et al. Gelatin tannate ameliorates acute colitis in mice by reinforcing mucus layer and modulating gut microbiota composition: emerging role for 'gut barrier protectors' in IBD? United Eur Gastroenterol J. 2014;2: $113-22$.

94. de Servi B, Moreira Da Silva R, Meloni M. New insights into the mechanism of action of gelatine tannate for acute diarrhoea. Part 2: antibacterial activity [Abstract]. In: 33rd Congress of the Groupe Francophone d'Hépato-Gastroentérologie et Nutrition Pédiatriques; 2012; Nantes, France. www. tasectan.ie. Accessed 13 Mar 2021.

95. Frasca G, Cardile V, Puglia C, et al. Gelatin tannate reduces the proinflammatory effects of lipopolysaccharide in human intestinal epithelial cells. Clin Exp Gastroenterol. 2012;5:61-7.

96. Bheemachari JAK, Joshi NH, Suresh DK, et al. Antidiarrheal evaluation of Ficus racemose Linn. latex. Acta Pharm Sci. 2007;49:133-8.

97. Souza SM, Aquino LC, Milach AC Jr, et al. Antiinflammatory and antiulcer properties of tannins from Myracrodruon urundeuva Allemão (Anacardiaceae) in rodents. Phytother Res. 2007;21:220-5.

98. Szajewska H, Hoekstra JH, Sandhu B. Management of acute gastroenteritis in Europe and the impact of the new recommendations: a multicenter study. The Working Group on Acute Diarrhoea of the European Society for Paediatric Gastroenterology, Hepatology, and Nutrition. J Pediatr Gastroenterol Nutr. 2000;30(5):522-7.

99. Uhlen S, Toursel F, Gottrand F. Association française de pédiatrie ambulatoire. Treatment of acute diarrhea: prescription patterns by private practice pediatricians [Traitement des diarrhées aiguës: les habitudes de prescription des pédiatres libéraux]. Archives de pédiatrie: organe officiel de la Sociéte française de pédiatrie. 2004;11:903-7.

100. Hou FQ, Wang Y, Li J, et al. Management of acute diarrhea in adults in China: a cross-sectional survey. BMC Public Health. 2013;13:41.

101. Pérez-Gaxiola G, Cuello-García CA, Florez ID, et al. Smectite for acute infectious diarrhoea in children. Cochrane Database Syst Rev. 2018;4:CD011526102.

102. González R, de Medina FS, Martínez-Augustin O, et al. Anti-inflammatory effect of diosmectite in hapten-induced colitis in the rat. Br J Pharmacol. 2004;141:951-60.

103. Song ZH, Ke YL, Xiao K, et al. Diosmectite-zinc oxide composite improves intestinal barrier restoration and modulates TGF- $\beta 1$, ERK1/2, and Akt 
in piglets after acetic acid challenge. J Anim Sci. 2015;93:1599-607.

104. Dupont C, Foo JL, Garnier P, et al. Oral diosmectite reduces stool output and diarrhea duration in children with acute watery diarrhea. Clin Gastroenterol Hepatol. 2009;7:456-62.

105. Mahraoui L, Heyman M, Plique O, et al. Apical effect of diosmectite on damage to the intestinal barrier induced by basal tumour necrosis factor-alpha. Gut. 1997;40:339-43.

106. Buccigrossi V, Russo C, Guarino A, de Freitas MB, Guarino A. Mechanisms of antidiarrhoeal effects by diosmectite in human intestinal cells. Gut Pathog. 2017;9:23.

107. Eutamene $H$, Beaufrand $C$, Mathieux-Fortunet $H$, et al. Diosmectite chronic treatment suppresses gut visceral hypersensitivity and intestinal transit acceleration induced by chronic stress in rat. United European Gastroenterol J. 2017;5(5S):A332(P0475).

108. Theodorou V, Fioramonti J, Droy-Lefaix MT, et al. Protective action of diosmectite treatment on digestive disturbances induced by intestinal anaphylaxis in the guinea-pig. Aliment Pharmacol Ther. 1994;8:295-9.

109. Kobyliak N, Abenavoli L, Falalyeyeva T, et al. Efficacy of probiotics and smectite in rats with nonalcoholic fatty liver disease. Ann Hepatol. 2018;17: 153-61.

110. Cao S, Wang L, Jiao L, et al. Effects of diosmectiteLactobacillus acidophilus on growth performance, intestine microbiota, mucosal architecture of weaned pigs. Anim Feed Sci Technol. 2016;220: 180-6.

111. Klem F, Wadhwa A, Prokop LJ, et al. Prevalence, risk factors, and outcomes of irritable bowel syndrome after infectious enteritis: a systematic review and meta-analysis. Gastroenterology. 2017;152(1042-1054):e1.

112. DuPont HL, Sullivan P, Pickering LK, et al. Symptomatic treatment of diarrhea with bismuth subsalicylate among students attending a Mexican university. Gastroenterology. 1977;73(4 Pt 1): 715-8.

113. Ericsson CD. Travellers' diarrhoea. Int J Antimicrob Agents. 2003;21:11624.

114. Bowen A, Agboatwalla M, Pitz A, et al. Effect of bismuth subsalicylate vs. placebo on use of antibiotics among adult outpatients with diarrhea in Pakistan: a randomized clinical trial. JAMA Netw Open. 2019;2(8):e199441.
115. Rendi-Wagner P, Kollaritsch H. Drug prophylaxis for travelers' diarrhea. Clin Infect Dis. 2002;34: 628-33.

116. Steffen R. Worldwide efficacy of bismuth subsalicylate in the treatment of travelers' diarrhea. Rev Infect Dis. 1990;12(Suppl 1):S80-6.

117. World Health Organization. Global Action Plan on Antimicrobial Resistance. Geneva, Switzerland: World Health Organization; 2015. https://apps. who.int/iris/bitstream/handle/10665/193736/ 9789241509763_eng.pdf?sequence $=1$. Accessed 3 Jan 2020.

118. Iakovenko EP, Agafonova NA, Pokhal'skaia OI, et al. The use of bismuth tripotassium dicitrate (De-Nol), a promising line of pathogenetic therapy for irritated bowel syndrome with diarrhea. Klin Med (Mosk). 2008;86:47-52.

119. Nguyen GC, Smalley WE, Vege SS, Carrasco-Labra A. Clinical Guidelines Committee. American Gastroenterological Association Institute Guideline on the Medical Management of Microscopic Colitis. Gastroenterology. 2016;150:242-6 (quiz e17-8).

120. Fine KD, Lee EL. Efficacy of open-label bismuth subsalicylate for the treatment of microscopic colitis. Gastroenterology. 1998;114:29-36.

121. Fine K, Lee E, Lafon G. Randomized double-blind, placebo-controlled trial of bismuth subsalicylate for microscopic colitis. Gastroenterology. 1999;116: A880.

122. Gentile NM, Khanna S, Loftus EV, Tremaine WJ, Kammer PP, Pardi DS. outcomes of patients with microscopic colitis treated with bismuth subsalicylate. Gastroenterology. 2015;148(4):Su1353(S483).

123. Hansen PB, Penkowa M. Bismuth adjuvant ameliorates adverse effects of high-dose chemotherapy in patients with multiple myeloma and malignant lymphoma undergoing autologous stem cell transplantation: a randomised, double-blind, prospective pilot study. Support Care Cancer. 2017;25:1279-89.

124. Hansen PB, Penkowa M. Retraction Note to: Bismuth adjuvant ameliorates adverse effects of highdose chemotherapy in patients with multiple myeloma and malignant lymphoma undergoing autologous stem cell transplantation: a randomised, double-blind, prospective pilot study. Support Care Cancer. 2021;29:533-4.

125. Wolf DC, Wolf CH, Rubin DT. Temporal improvement of a COVID-19-Positive Crohn's disease patient treated with bismuth subsalicylate. Am J Gastroenterol. 2020;11:1298. 
126. Casburn-Jones AC, Farthing MJG. Management of infectious diarrhoea. Gut. 2004;53:296-305.

127. Lambert JR. Pharmacology of bismuth-containing compounds. Rev Infect Dis. 1991;13(Suppl 8): S691-5.

128. Condratovici CP, Bacarea V, Piqué N. Xyloglucan for the treatment of acute gastroenteritis in children: results of a randomized, controlled, clinical trial. Gastroenterol Res Pract. 2016;2016:6874207.

129. Santos J, Musta V, Luca CM, Belei OA, Cambrea SC. Randomized, placebo-controlled trial of xyloglucan and gelose for the treatment of acute diarrhea in children. Expert Rev Gastroenterol Hepatol. 2020;19:1-7.

130. Trifan A, Burta O, Tiuca N, Petrisor DC, Lenghel A, Santos J. Efficacy and safety of Gelsectan for diarrhoea-predominant irritable bowel syndrome: a randomised, crossover clinical trial. United Eur Gastroenterol J. 2019;7:1093-101.

131. Alexea O, Bacarea V, Piqué N. The combination of oligo- and polysaccharides and reticulated protein for the control of symptoms of patients with irritable bowel syndrome: Results of a randomized, placebo-controlled, double-blind, parallel group, multicentre clinical trial. United Eur Gastroenterol J. 2016;4:455-65.

132. Durbán Reguera F, López-Argüeta Álvarez S, López Montes J, et al. Prospective observational study on infants and children with acute diarrhoea treated with gelatin tannate ${ }^{\circledR}$ [Abstract and poster]. Semana de las Enfermedades Digestivas Congress; 2007b Jun; Madrid, Spain. www.tasectan.ie/index.php/ healthcareprofessionals. Accessed 13 Mar 2021.

133. Aloi M, Pofi F, Tolone C, et al. Gelatin tannate as treatment for acute diarrhea in children: a prospective, randomized, parallel study. Dig Liver Dis. 2013;45(Suppl 4):e279.

134. Mennini M, Tolone C, Frassanito A, et al. Gelatin tannate for acute childhood gastroenteritis: a randomized, single-blind controlled trial. Paediatr Drugs. 2017; 19:131-7.

135. Cagan E, Ceylan S, Mengi S, et al. Evaluation of gelatin tannate against symptoms of acute diarrhea in pediatric patients. Med Sci Monit. 2017;23: 20292034.

136. Kara SS, Volkan B, Erten I. The therapeutic effect of gelatin tannate in acute diarrhea in children. Turk J Pediatr. 2017;59:531-6.

137. Serban ED, Manolache M. Gelatin tannate versus other antidiarrheal medication in children with acute gastroenteritis: a retrospective, observational study. J Comp Eff Res. 2019;8:187-94.

138. Kołodziej M, Bebenek D, Konarska Z, et al. Gelatine tannate in the management of acute gastroenteritis in children: a randomised controlled trial. BMJ Open. 2018;8(5):e020205.

139. Durbán Reguera F, López-Argüeta Álvarez S, López Montes J, et al. Prospective observational study on adults with acute diarrhoea treated with gelatin tannate ${ }^{\circledR}$ [Abstract and poster]. In: Semana de las Enfermedades Digestivas Congress; 2007a Jun; Madrid, Spain. Available from: www.tasectan.ie/ index.php/healthcare-professionals. Accessed 13 Mar 2021.

140. Allegrini A, Costantini M. Gelatine tannate for the treatment of acute diarrhoea in adults. J Gastroint Dig Syst. 2012;2:3.

141. Ruszczyński M, Urbańska M, Szajewska H. Gelatin tannate for treating acute gastroenteritis: a systematic review. Ann Gastroenterol. 2014;27:121-4.

142. Florez ID, Sierra JM, Niño-Serna LF. Gelatin tannate for acute diarrhoea and gastroenteritis in children: a systematic review and meta-analysis. Arch Dis Child. 2020;105:141-6.

143. Lopetuso L, Graziani C, Guarino A, et al. Gelatin tannate and tyndallized probiotics: a novel approach for treatment of diarrhea. Eur Rev Med Pharmacol Sci. 2017;21:873-83.

144. Piqué N, Berlanga M, Miñana-Galbis D. Health benefits of heat-killed (Tyndallized) probiotics: an overview. Int J Mol Sci. 2019;20:2534.

145. Vivatvakin B, Jongpipatvanich S, Harikul S, et al. Control study of oral rehydration solution (ORS)/ ORS + dioctahedral smectite in hospitalized Thai infants with acute secretory diarrhea. Southeast Asian J Trop Med Public Health. 1992;23:414-9.

146. Lexomboon U, Harikul S, Lortholary O. Control randomized study of rehydration/rehydration with dioctahedral smectite in ambulatory Thai infants with acute diarrhea. Southeast Asian J Trop Med Public Health. 1994;25:157-62.

147. Narkeviciute I, Rudzeviciene O, Leviniene G, et al. Management of Lithuanian children's acute diarrhoea with Gastrolit solution and dioctahedral smectite. Eur J Gastroenterol Hepatol. 2002;14: 419-24.

148. Mujawar QM, Naganoor R, Ali MD, et al. Efficacy of dioctahedral smectite in acute watery diarrhea in Indian children: a randomized clinical trial. J Trop Pediatr. 2012;58:63-7. 
149. Dupont C, Moreno JL, Barau E, et al. Effect of diosmectite on intestinal permeability changes in acute diarrhea: a double-blind placebo-controlled trial. J Pediatr Gastroenterol Nutr. 1992;14:413-9.

150. Madkour AA, Madina EM, El-Azzouni OE, et al. Smectite in acute diarrhea in children: a doubleblind placebo-controlled clinical trial. J Pediatr Gastroenterol Nutr. 1993;17:176-81.

151. Guarino A, Bisceglia M, Castellucci G, Italian Society of Pediatric Gastroenterology and Hepatology Study Group for Smectite in Acute Diarrhea, et al. Smectite in the treatment of acute diarrhea: a nationwide randomized controlled study of the Italian Society of Pediatric Gastroenterology and Hepatology (SIGEP) in collaboration with primary care pediatricians. SIGEP Study Group for Smectite in Acute Diarrhea. J Pediatr Gastroenterol Nutr. 2001;32:71-5.
152. Yao-Zong Y, Shi-Rong L, Delvaux M. Comparative efficacy of dioctahedral smectite (Smecta) and a probiotic preparation in chronic functional diarrhoea. Dig Liver Dis. 2004;36:824-8.

153. Dumitrascu DL, Stanculete M, Mitrea I, et al. The effect of two antidiarrhoeal drugs on the psychosocial adjustment to illness in chronic functional diarrhoea. Rom J Intern Med. 2004;42:191-7.

154. Chang FY, Lu CL, Chen CY, et al. Efficacy of dioctahedral smectite in treating patients of diarrheapredominant irritable bowel syndrome. J Gastroenterol Hepatol. 2007;22:2266-72.

155. https://commons.wikimedia.org/wiki/File: Hemicellulose.png. Accessed 13 Mar 2021. 